\title{
Antifouling performance of poly(lysine methacrylamide)-grafted PVDF microfiltration membrane for solute separation
}

\author{
Dapeng Liu, Jing Zhu, Ming Qiu, Chunju He* \\ State Key Laboratory for Modification of Chemical Fibers and Polymer Materials \\ College of Materials Science and Engineering \\ Donghua University \\ Shanghai, 201620, P.R. China \\ *Corresponding author: Chunju He, chunjuhe@dhu.edu.cn
}

TEL: 86-21-67792842

FAX: 86-21-67792855

\begin{abstract}
In this work, antifouling poly(vinylidene fluoride) (PVDF) microfiltration membrane was fabricated via surface activation by atmosphere plasma treatment and subsequently surface-initiated atom transfer radical polymerization (SI-ATRP). Zwitterionic poly(lysine methacrylamide) (LysAA) brushes were successfully grafted onto membrane surface as confirmed by Fourier-transform infrared spectrometer (FTIR) and X-ray photoelectron spectroscopy (XPS). The wetting ability of the graft membranes was improved significantly with water contact angle decreased from $121.6^{\circ}$ to as low as $29.0^{\circ}$. The graft membranes also exhibited enhanced anti-protein-fouling and anti-oil-fouling properties with water flux recovery ratios as high as $86 \%$ and $82 \%$ respectively. This work provides a substrate-independent method for the fabrication of antifouling membranes with well-defined pLysAA brushes, which may find applications in protein separation, water treatment and oil/water separation, etc.
\end{abstract}


Keywords: plasma treatment; amino acid; zwitterionic; poly(vinylidene fluoride); poly(lysine methacrylamide)

\section{Introduction}

As one of the most popular separation technologies, membrane technology has been widely used for wastewater treatment, agro-food, biotechnological and biomedical markets due to its low energy consumption, high process efficiency, easy scale-up and negligible environmental impact [1,2]. However, membrane fouling exists in almost all membrane filtration processes, which leads to decreased life span and increased operation cost [3]. Therefore, preparation of antifouling or low-fouling membranes has become one of the essential issues of membrane science.

It is generally accepted that an increase in membrane hydrophilicity offers improved fouling resistance since most of foulants and proteins in nature are hydrophobic [4]. Therefore, various materials have been employed to enhance the hydrophilicity properties of membranes via blending, grafting or coating method. These materials includes poly(ethylene glycol)(PEG) [5-7], polyvinyl pyrrolidone (PVP) [8-10], poly(acrylamide) [11,12], poly(hydroxyethyl methacrylate) [13-15], polysaccharide [16] and zwitterionic materials such as poly(sulfobetaine) [17-19], poly(carboxybetaine) [20,21] and poly(phosphobetaine) [22]. Among them, zwitterionic materials have drawn the most attention due to their ultralow fouling properties, which is attributed to their ability to bind a significant number of water 
molecules through both electrostatic and hydrogen bonding interactions [23]. Recently, amino acid-based materials have drawn increasing attention due to their zwitterionic and biomimetic nature. Several amino acids in small-molecule form have been employed for the modification of porous membranes via carbodiimide chemistry or esterification reaction [23-25]. However, these works focused on short chain amino acids or amino acids with zwitterionic structure being destroyed during the modification process, which may limit the antifouling properties of the resultant membranes since the density, chain length and the zwitterionic structure of the modifier play an important role in its antifouling ability [26,27].

Atom transfer radical polymerization (ATRP) has been frequently used to control the grafting chain length and grafting density in membrane modification due to its effective and convenient characteristics. Although it is believed that ATRP is not suitable for the preparation of amino acid based zwitterionic polymers since the heavy metal ion (i.e. $\mathrm{Cu}$ catalyst for ATRP) may cause severe monomer precipitation, Alswieleh and coworkers have successfully grafted poly(cysteine methacrylate), a cysteine based zwitterionic polymer, from the surface of silicon wafers by ATRP [28], which inspires us that other amino acid based monomers may also polymerized with ATRP.

In this article, PVDF microfiltration membrane with enhanced antifouling ability was fabricated via surface activation by atmosphere plasma treatment and subsequently surface grafting. Zwitterionic poly(lysine methacrylamide) brushes were grafted onto membrane surface by using atom transfer radical polymerization method, 
which is known to be an effective and convenient way for the synthesis of uniform polymer brushes. Upon modification, the surface chemical composition, surface hydrophilicity, permeability as well as fouling properties of the virgin and modified membranes were investigated in detail.

\section{Experimental}

\subsection{Materials}

PVDF microporous membranes with a diameter of $50 \mathrm{~mm}$, a thickness of $70 \mu \mathrm{m}$ and an average pore size of $0.2 \mu \mathrm{m}$ were supplied by Tao Yuan Inc. (Haining, China). L-Lysine hydrochloride (98\%), 2-bromoisobutyryl bromide (BIBB, 98\%), cupric carbonate basic, 8-hydroxyquinoline (98\%), methacryloyl chloride (97\%), Copper (I) bromide $(\mathrm{CuBr}, 98 \%)$ and 2,2'-bipyridyl (Bpy, 99.5\%) were obtained from Energy Chemical (Shanghai, China). Bovine serum albumin (BSA), tetrahydrofuran, Triethylamine, dichloromethane, chloroform, acetone, methanol, ethanol, ether and potassium hydroxide were all purchased from Sinopharm Chemical Reagent (Shanghai, China). Triethylamine and tetrahydrofuran were evaporated before use. Copper (I) bromide was purified according to a reported procedure [29]. All other chemicals were used without further purification.

\subsection{Preparation of oil/water emulsion}

Oil/water emulsion was prepared by dissolving $10.0 \mathrm{~g}$ soybean oil in $1 \mathrm{~L}$ deionized water and sonicated for $30 \mathrm{~min}$ to obtain a milky solution. The particle size distribution of the oil/water emulsion was characterized by dynamic laser light scattering (DLLS, BI-200SM, USA). 


\subsection{Preparation of lysine methacrylamide}

Lysine methacrylamide (LysAA) was prepared through the reaction of lysine with methacryloyl chloride similar to a literature published previously [30,31]. L-Lysine hydrochloride (20.0 g, $109.6 \mathrm{mmol})$ and basic cupric carbonate $(13.4 \mathrm{~g}, 60.2 \mathrm{mmol})$ were firstly added to $200 \mathrm{~mL}$ of water and stirred at $90{ }^{\circ} \mathrm{C}$ for $10 \mathrm{~min}$. After the insoluble residue was filtered, $\mathrm{KOH}$ aqueous solution $(2.0 \mathrm{M}, 116.0 \mathrm{~mL})$ and acetone $(116.0 \mathrm{~mL})$ were added into the filtration followed by the addition of methacryloyl chloride $(14.3 \mathrm{~mL}, 137 \mathrm{mmol})$ at $4{ }^{\circ} \mathrm{C}$ for $1 \mathrm{~h}$. The solution was stirred at room temperature for $15 \mathrm{~h}$. Then blue precipitate (methacryloyl lysine copper complex) in the solution was collected and washed extensively with water, methanol and ether.

After that, the blue powder was added to a solution of 8-hydroxyquinolinol (5.7 $\mathrm{g}$, $39.3 \mathrm{mmol})$ in chloroform $(200 \mathrm{~mL})$ followed by the addition of $200 \mathrm{~mL}$ of deionized water. After shaking over night at $25{ }^{\circ} \mathrm{C}$, the green precipitate in the solution was removed. Then LysAA was collected from the water layer via lyophilization as a white powder. ${ }^{1} \mathrm{H}$ NMR $\left(\mathrm{D}_{2} \mathrm{O}, \delta \mathrm{ppm}\right): 5.49\left(\mathrm{~s}, 1 \mathrm{H}, \mathrm{CH}_{2}=\mathrm{C}\right), 5.25\left(\mathrm{~s}, 1 \mathrm{H}, \mathrm{CH}_{2}=\mathrm{C}\right)$, $3.55(\mathrm{t}, 1 \mathrm{H}, \mathrm{CH}), 3.10\left(\mathrm{t}, 2 \mathrm{H}, \mathrm{CH}_{2}\right), 1.75\left(\mathrm{~s}, 3 \mathrm{H}, \mathrm{CH}_{3}\right), 1.70\left(\mathrm{~m}, 2 \mathrm{H}, \mathrm{CH}_{2}\right), 1.45(\mathrm{~m}$, $\left.2 \mathrm{H}, \mathrm{CH}_{2}\right), 1.24\left(\mathrm{~m}, 2 \mathrm{H}, \mathrm{CH}_{2}\right)$.

\subsection{Membrane preparation}

The PVDF membrane was firstly treated by atmospheric pressure plasma in air for 100 seconds with input power of $250 \mathrm{~W}$ controlled by a $13.56 \mathrm{MHz} \mathrm{RF}$ generator (CTP-2000K, Nanjing Sunan, China). 
Two pieces of the plasma-treated membranes, triethylamine $(1.59 \mathrm{~g}, 15.8 \mathrm{mmol})$ and dichloromethane $(100 \mathrm{~mL})$ were placed into a $150 \mathrm{~mL}$ conical flask. 2-bromoisobutyryl bromide $(3.45 \mathrm{~g}, 15.0 \mathrm{mmol})$ was then added dropwise to the solution at $4{ }^{\circ} \mathrm{C}$ and stirred at room temperature for $12 \mathrm{~h}$. The resultant membranes were washed successively with dichloromethane, ethanol and water.

Finally, a series of zwitterionic pLysAA grafted membranes were prepared by surface initiated atom transfer radical polymerization (SI-ATRP). Bpy (0.063 g, 0.4 mmol) and a predetermined amount of LysAA monomer were dissolved in $50.0 \mathrm{~mL}$ of deionized water before two pieces of initiator-anchored membranes were added into the solution. Then a purified argon stream was introduced to degas the solution and $\mathrm{CuBr}(0.028 \mathrm{~g}, 0.2 \mathrm{mmol})$ was added into the flask under argon atmosphere. After three freeze-pump-thaw cycles, the flask was sealed and placed in a thermostatic bath at $40{ }^{\circ} \mathrm{C}$ under constant stirring for $24 \mathrm{~h}$. The resultant membrane was rinsed extensively with water and dried in a vacuum oven at room temperature. The grafting yield $\left(\mathrm{mg} \cdot \mathrm{cm}^{-2}\right)$ was determined by the weight increase after grafting polymerization. The resultant membranes were marked by $\mathrm{M}-3$ and M-5 corresponding to different monomer contents of $0.03 \mathrm{~g} \cdot \mathrm{mL}^{-1}$ and $0.05 \mathrm{~g} \cdot \mathrm{mL}^{-1}$ respectively. For comparison, the virgin membrane, plasma-treated membrane and initiator-anchored membrane were marked by $\mathrm{M}-0, \mathrm{M}-\mathrm{OH}$ and $\mathrm{M}-\mathrm{Br}$ respectively.

\subsection{Membrane characterization}

Fourier-transform infrared spectrometer (FTIR, Nicolet 8700, USA) with zinc 
selenide $(\mathrm{ZnSe})$ as an internal reflection element was used to detect the chemical composition of the virgin and modified membranes. The spectra were captured by averaging 32 scans at a resolution of $4 \mathrm{~cm}^{-1}$. The surface composition of the membranes was also characterized by X-ray photoelectron spectroscopy (XPS) performed on a Thermal Scientific K-Alpha spectrometer with a monochromated Al K X-ray source (1486.6 eV photons). The XPS spectra were obtained at a take-off angle of $45^{\circ}$ with respect to the membrane surface. The surface morphology of the membranes was observed by scanning electron microscopy (SEM, HITACHI S-3000, Japan) operating at an acceleration voltage of $10.0 \mathrm{kV}$ and atomic force microscopy (AFM, BioScope Catalyst, USA) with tapping mode. The average pore size of the virgin and modified membranes was detected and analyzed with mercury porosimetry method using a mercury porosimeter (Micromeritics Autopore IV, USA).

Static water contact angles (WCA) of the membranes were measured using a telescopic goniometer (Dataphysics OCA40, Germany) at $25{ }^{\circ} \mathrm{C} .3 \mu \mathrm{L}$ of deionized water was dropped on the sample surface at five different sites and the average value was taken. Water uptake was used to evaluate the hydration capacities of the membranes, which was defined as the weight difference between the wet membrane and the dry membrane divided by the surface area.

The mechanical properties of the virgin and modified membranes were characterized by universal testing machine (KEXIN, WDW3020, China) under wet state at tensile speed of $20 \mathrm{~mm} \cdot \mathrm{min}^{-1}$. Each sample was tested at least 5 times and the average value was taken. 


\subsection{Filtration experiments}

The permeation and separation properties of the virgin and modified membranes were characterized using a dead-end filtration system connected with a peristaltic pump and a solution reservoir at a constant trans-membrane pressure of $0.1 \mathrm{MPa}$, as shown in Fig. 1. Each membrane with an area of $17.3 \mathrm{~cm}^{2}$ was initially pressured with deionized water at a pressure of $0.15 \mathrm{MPa}$ for $30 \mathrm{~min}$ before the pressure was reduced to $0.1 \mathrm{MPa}$. The initial water flux $\left(\mathrm{J}_{\mathrm{w}}\right)$ was recorded after the flux became steady. After that, the feed solution was replaced by $1.0 \mathrm{~g} \cdot \mathrm{L}^{-1}$ BSA solution in phosphate buffer solution (PBS, pH 7.4) or oil/water emulsion, and BSA solution flux ( $\left.\mathrm{J}_{\mathrm{BSA}}\right)$ and oil/water emulsion flux $\left(\mathrm{J}_{\mathrm{o} / \mathrm{w}}\right)$ were recorded accordingly. The pure water flux, BSA solution flux and oil/water emulsion flux were calculated by the following equation:

$\mathrm{J}=\frac{\mathrm{V}}{\mathrm{S} \times \mathrm{t}}$

where the parameters of $\mathrm{J}, \mathrm{V}, \mathrm{S}$, and $\mathrm{t}$ denote the relevant flux $\left(\mathrm{L} \cdot \mathrm{m}^{-2} \cdot \mathrm{h}^{-1}\right)$, the permeate volume $(\mathrm{L})$, membrane area $\left(\mathrm{m}^{2}\right)$ and permeation time (h) respectively.

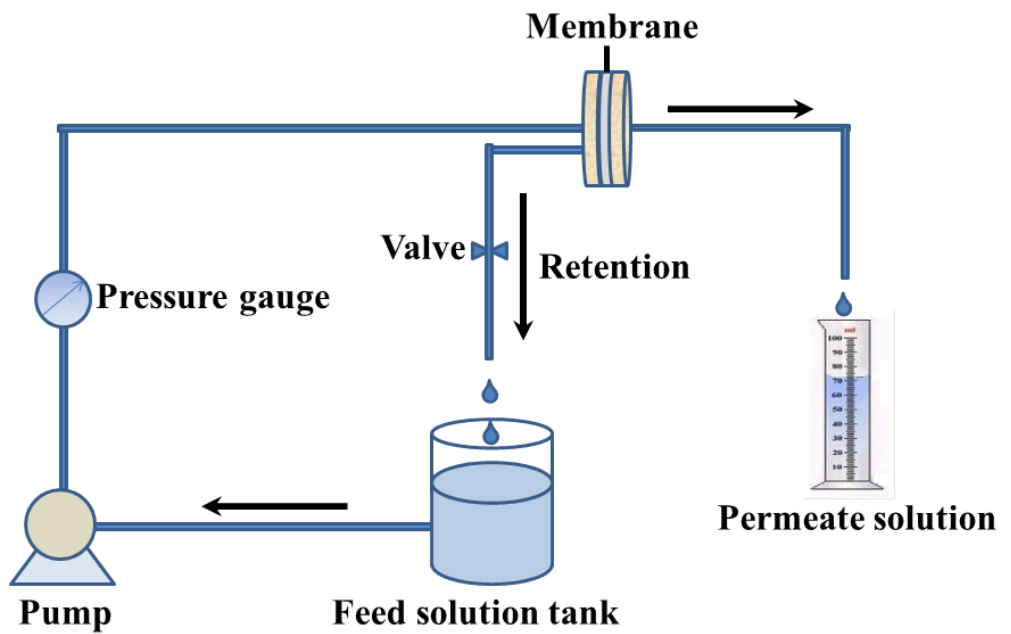

Fig. 1. Schematic diagram of the filtration system. 
The oil rejection of emulsified oil (R) was calculated by the following equation:

$\mathrm{R}=\left(1-\frac{\mathrm{C}_{\mathrm{p}}}{\mathrm{C}_{\mathrm{f}}}\right) \times 100 \%$

where the parameters of $\mathrm{C}_{\mathrm{p}}$ and $\mathrm{C}_{\mathrm{f}}$ represented oil content of the permeate and the feed respectively. Oil content in the emulsions was characterized by Total Organic Carbon analyzer (TOC-VCPH, Shimadzu, Japan).

\subsection{Antifouling evaluation}

To evaluate the antifouling properties of the virgin and modified membranes, static protein adsorption experiments were conducted with BSA as the model protein. The sample was firstly rinsed with ethanol and PBS buffer solution ( $\mathrm{pH} 7.4)$ for $30 \mathrm{~min}$ before immersed into $10.0 \mathrm{~mL}$ of BSA solution $\left(0.2 \mathrm{~g} \cdot \mathrm{L}^{-1}, \mathrm{pH} 7.4\right)$. Then the solution was incubated at $25 \pm 1{ }^{\circ} \mathrm{C}$ for $12 \mathrm{~h}$ to obtain adsorption equilibrium. The absorbance at $280 \mathrm{~nm}$ was determined by a UV-vis spectrophotometer (Shimadzu UV-1800, Japan).

To further evaluate the antifouling properties, the membranes were subjected to permeation tests using BSA and soybean oil as the model pollutants. The process was similar to the filtration experiments. Fluxes were recorded every $5 \mathrm{~min}$. After pressured at $0.15 \mathrm{MPa}$ for $30 \mathrm{~min}$, water flux was recorded within $30 \mathrm{~min}$. Then the feed was replaced by BSA solution or oil/water emulsion, and flux was recorded within $60 \mathrm{~min}$. After filtration of the foulant solutions, the membrane was rinsed with deionized water and $0.1 \mathrm{M} \mathrm{NaOH}$ solution for the BSA solution and oil/water 
emulsion respectively. Then pure water flux of the cleaned membrane was measured again. Water flux recovery ratio (Frr ) was calculated by the following equation:

$\operatorname{Frr}=\frac{\mathbf{J}_{\mathrm{w} 2}}{\mathrm{~J}_{\mathrm{w} 1}} \times 100 \%$

where the parameters of $J_{w 1}$ and $J_{w 2}$ denote the initial pure water flux $\left(\mathrm{L} \cdot \mathrm{m}^{-2} \cdot \mathrm{h}^{-1}\right)$ and the pure water flux of the cleaned membrane $\left(\mathrm{L} \cdot \mathrm{m}^{-2} \cdot \mathrm{h}^{-1}\right)$.

The antifouling properties of the virgin and modified membranes were also assessed by the total fouling ratio $\left(R_{t}\right)$, the reversible fouling ratio $\left(R_{r}\right)$ and the irreversible fouling ratio $\left(\mathrm{R}_{\mathrm{ir}}\right)$ :

$$
\begin{aligned}
& \mathrm{R}_{\mathrm{t}}=\left(1-\frac{\mathrm{J}_{\mathrm{p}}}{\mathrm{J}_{\mathrm{w} 1}}\right) \times 100 \% \\
& \mathrm{R}_{\mathrm{r}}=\frac{\mathrm{J}_{\mathrm{w} 2}-\mathrm{J}_{\mathrm{p}}}{\mathrm{J}_{\mathrm{w} 1}} \times 100 \% \\
& \mathrm{R}_{\mathrm{ir}}=\frac{\mathrm{J}_{\mathrm{w} 1}-\mathrm{J}_{\mathrm{w} 2}}{\mathrm{~J}_{\mathrm{w} 1}} \times 100 \%
\end{aligned}
$$

where $J_{p}$ denotes the flux $\left(\mathrm{L} \cdot \mathrm{m}^{-2} \cdot \mathrm{h}^{-1}\right)$ of the pollutant i.e. BSA solution or oil/water emulsion.

\section{Results and discussion}




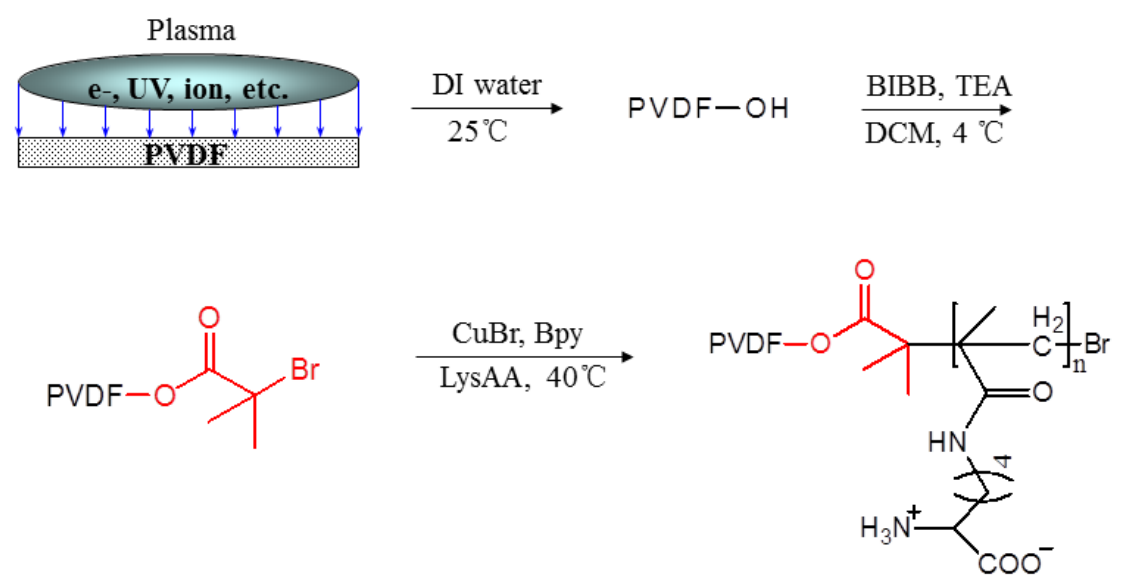

Fig. 2. Preparation process of zwitterionic pLysAA grafted membranes.

In order to improve the antifouling properties of hydrophobic PVDF membrane, amino acid-based zwitterionic pLysAA brushes were introduced via surface activation and SI-ATRP. The preparation process of the modified membranes is presented in Fig. 2. Atmospheric plasma was firstly employed for the treatment of PVDF membrane, which is easily oxidized in air after plasma treatment and a variety of polar groups such as hydroxyl and amino groups can be produced on the surface [32]. Then the polar groups produced on the surface were used for the immobilization of alkyl halide ATRP initiator. Subsequently, zwitterionic pLysAA brushes were grown from the initiator sites via SI-ATRP.

\subsection{Surface grafting}

Grafting yield of the grafted polymer plays a dominant role in controlling the fouling property of membranes. With SI-ATRP, the grafting yield can be adjusted conveniently by varying monomer content in the reacting solution. Therefore the relationship between grafting yield and monomer content in the aqueous solution was investigated, which was calculated by the weight increase per area after surface 
modification. As shown in Fig. 3, the grafting yield of the graft membranes increases monotonically with LysAA concentration, indicating that membranes with proper grafting yield can be easily fabricated by varying monomer concentration in the reaction solution.

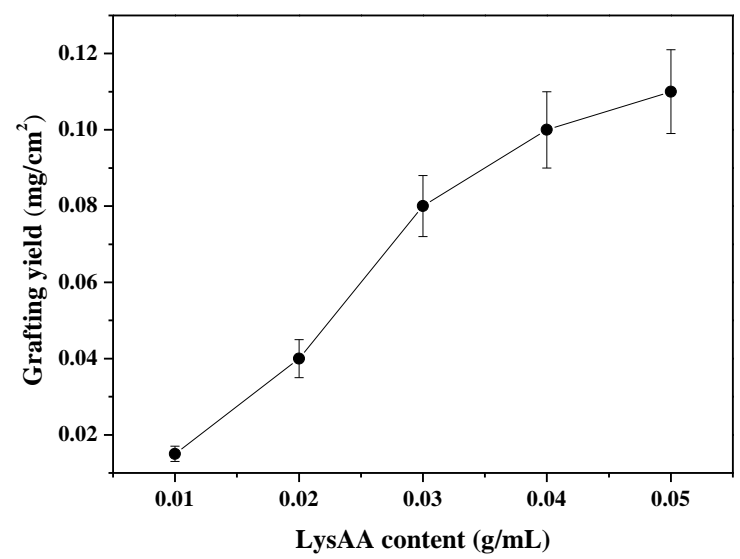

Fig. 3. Effect of monomer content in the reaction solution on grafting yield.

\subsection{Surface chemical composition}

The surface chemical compositions of the virgin and modified membranes were detected by ATR-FTIR and XPS, as shown in Fig. 4. For the graft membranes, compared with the other membranes, the new absorption peaks at $1621 \mathrm{~cm}^{-1}$ and 1530 $\mathrm{cm}^{-1}$ can be ascribed to the bands of $\mathrm{C}=\mathrm{O}$ stretching (amide I) and $\mathrm{N}-\mathrm{H}$ bending (amide II) respectively [33]. The peak at $3340 \mathrm{~cm}^{-1}$ can be assigned to N-H stretching vibrations [30]. The presence of these groups indicates successful immobilization of zwitterionic pLysAA brushes on membrane surface. The intensity of these peaks with M-5 is obviously higher than that of M-3, which confirms the grafting yield increases with monomer concentration. However, no apparent differences can be seen for the 
membranes of $\mathrm{M}-0, \mathrm{M}-\mathrm{OH}$ and $\mathrm{M}-\mathrm{Br}$ since ATR-FTIR is not very surface sensitive due to its large penetration depth [34].
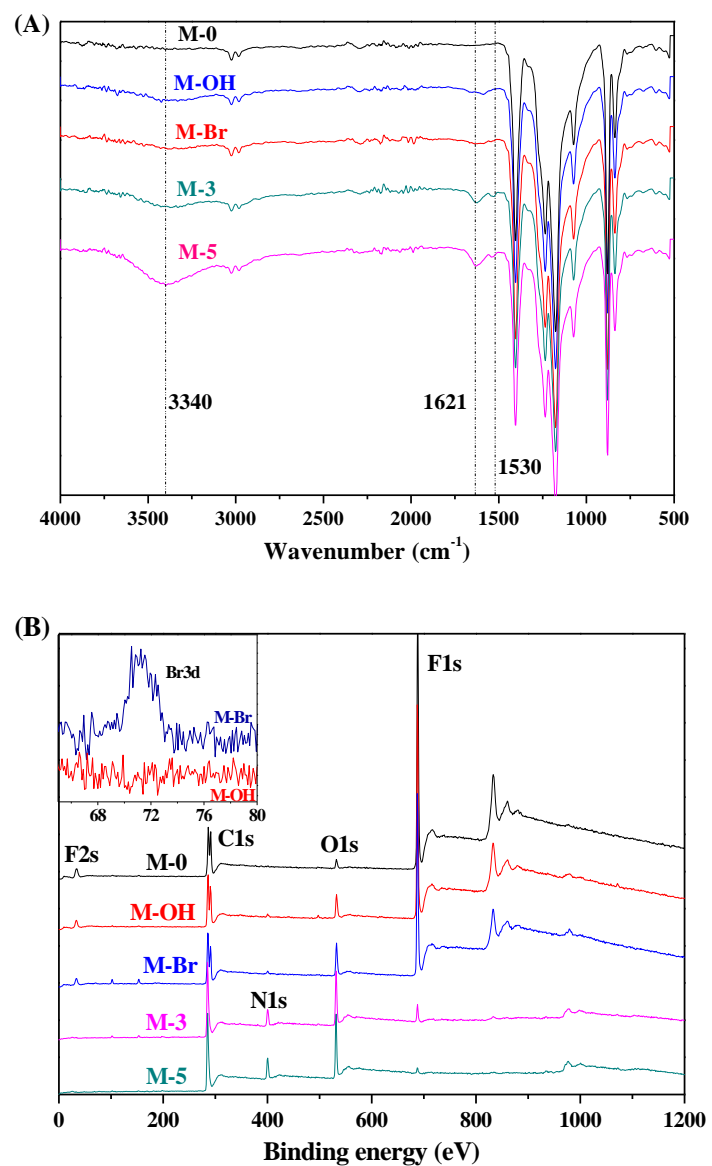

Fig. 4. FTIR spectra (A) and wide-scan XPS spectra (B) for the virgin and modified membranes.

As shown in Fig. 4B, there are three main peaks with bind energies of $286.6 \mathrm{eV}$, $532.6 \mathrm{eV}$ and $688.2 \mathrm{eV}$, which can be ascribed to $\mathrm{C} 1 \mathrm{~s}, \mathrm{O} 1 \mathrm{~s}$ and $\mathrm{F} 1 \mathrm{~s}$ respectively. For $\mathrm{M}-\mathrm{Br}$, the appearance of $\mathrm{Br} 3 \mathrm{~d}$ peak at $70.4 \mathrm{eV}$ indicates that the initiator is successfully immobilized on membrane surface since 2-bromoisobutyryl bromide is the only source of bromine element. For the graft membranes i.e. M-3 and M-5, a new peak at $400.1 \mathrm{eV}$ appears, which can be attributed to the nitrogen atoms from pLysAA brushes. 

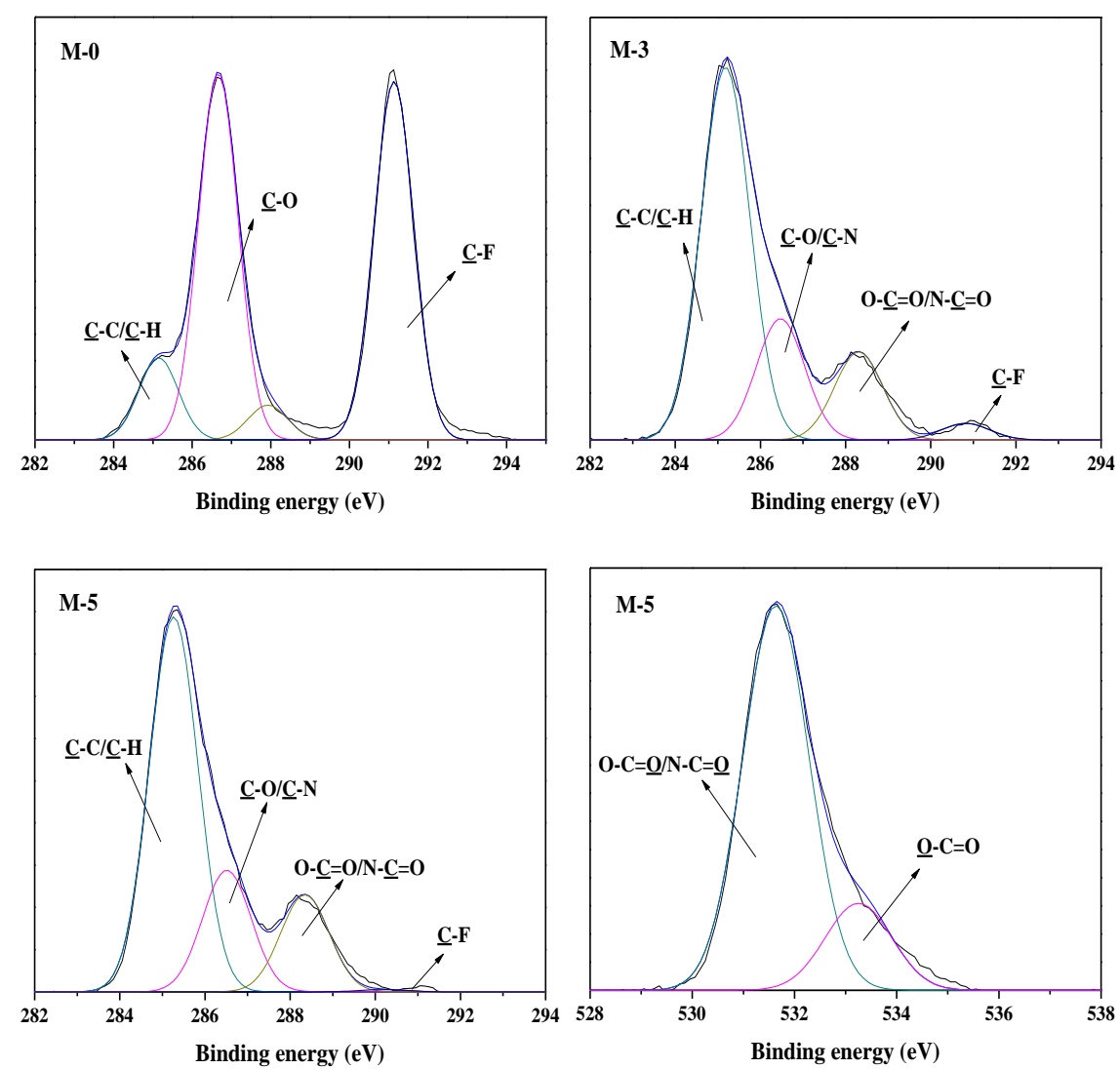

Fig. 5. XPS C1s and O1s core-level spectra for the virgin and modified membranes.

The XPS C1s and O1s core-level spectra for the virgin and modified membranes are presented in Fig. 5. It can be found that there are more than two peaks in the C1s spectrum of the virgin membrane, indicating that some additives such as PEG remain in the membranes. The C1s core-level spectra of the graft membranes can be curve fitted into four peak components with binding energies of $285.2 \mathrm{eV}, 286.7 \mathrm{eV}, 288.4$ $\mathrm{eV}$ and $290.8 \mathrm{eV}$ attributable to the $\mathrm{C}-\mathrm{C} / \mathrm{C}-\mathrm{H}, \mathrm{C}-\mathrm{O} / \mathrm{C}-\mathrm{N}, \mathrm{O}-\mathrm{C}=\mathrm{O} / \mathrm{N}-\mathrm{C}=\mathrm{O}$ and $\mathrm{C}-\mathrm{F}$ species respectively $[35,36]$. The O1s core-level spectrum of M-5 can be curve fitted into two peak components with binding energies of about $531.5 \mathrm{eV}$ and $533.4 \mathrm{eV}$ attributable to the $\mathrm{O}-\mathrm{C}=\underline{\mathrm{O}} / \mathrm{N}-\mathrm{C}=\underline{\mathrm{O}}$ and $\underline{\mathrm{O}}-\mathrm{C}=\mathrm{O}$ species respectively [13]. These results indicate that pLysAA brushes have been successfully grafted onto membrane surface.

Table 1 shows the relative elemental percentages of the virgin and modified 
membranes detected by XPS. After grafting polymerization, the relative amount of nitrogen atom is increased significantly to as high as $10.38 \%$, which is in accordance with the increasing amount of pLysAA brushes on the membrane surface. The relative atomic composition of fluorine on the graft membranes decreases with the increasing monomer concentration in the ATRP reaction solution. For the membrane of M-5, the relative atomic composition of fluorine reaches as low as $0.97 \%$, indicating that almost all the surface is covered by pLysAA brushes.

Table 1 Element composition (at. \%) on the membrane surface determined by XPS.

\begin{tabular}{cccccc}
\hline & \multicolumn{5}{c}{ Element (at. \%) } \\
\cline { 2 - 6 } Membrane & $\mathrm{C}$ & $\mathrm{F}$ & $\mathrm{O}$ & $\mathrm{N}$ & $\mathrm{Br}$ \\
\hline $\mathrm{nyyyyy}$ & 60.83 & 37.21 & 1.95 & - & - \\
$\mathrm{M}-\mathrm{OH}$ & 63.98 & 29.96 & 6.06 & - & - \\
$\mathrm{M}-\mathrm{Br}$ & 64.73 & 25.79 & 8.39 & 0.97 & 0.12 \\
$\mathrm{M}-3$ & 73.01 & 2.88 & 15.35 & 8.69 & 0.07 \\
$\mathrm{M}-5$ & 72.94 & 0.97 & 15.62 & 10.38 & 0.10 \\
\hline
\end{tabular}

\subsection{Surface morphology}

Although surface grafting is an effective way for the antifouling modification of membranes and different "live"/controlled methods have been employed to control the grafting density, most of them suffer from pore plugging leading to flux reduction [37]. As shown in Fig. 6, there are lots of large pores on the surface, beneath which are much smaller ones overlapping each other. However, no obvious differences can be seen among the membranes from the SEM images, indicating that neither the plasma treatment nor the grafting polymerization altered much the surface 
morphologies of the modified membranes. All of the membranes show relatively rough surface with surface roughness $(\mathrm{Sq})$ around $0.6 \mu \mathrm{m}$ (as shown in Fig. 7 and Table 2). The roughness of the membranes plays an important role in surface hydrophilicity, as illustrated by the well-known Wenzel equation.
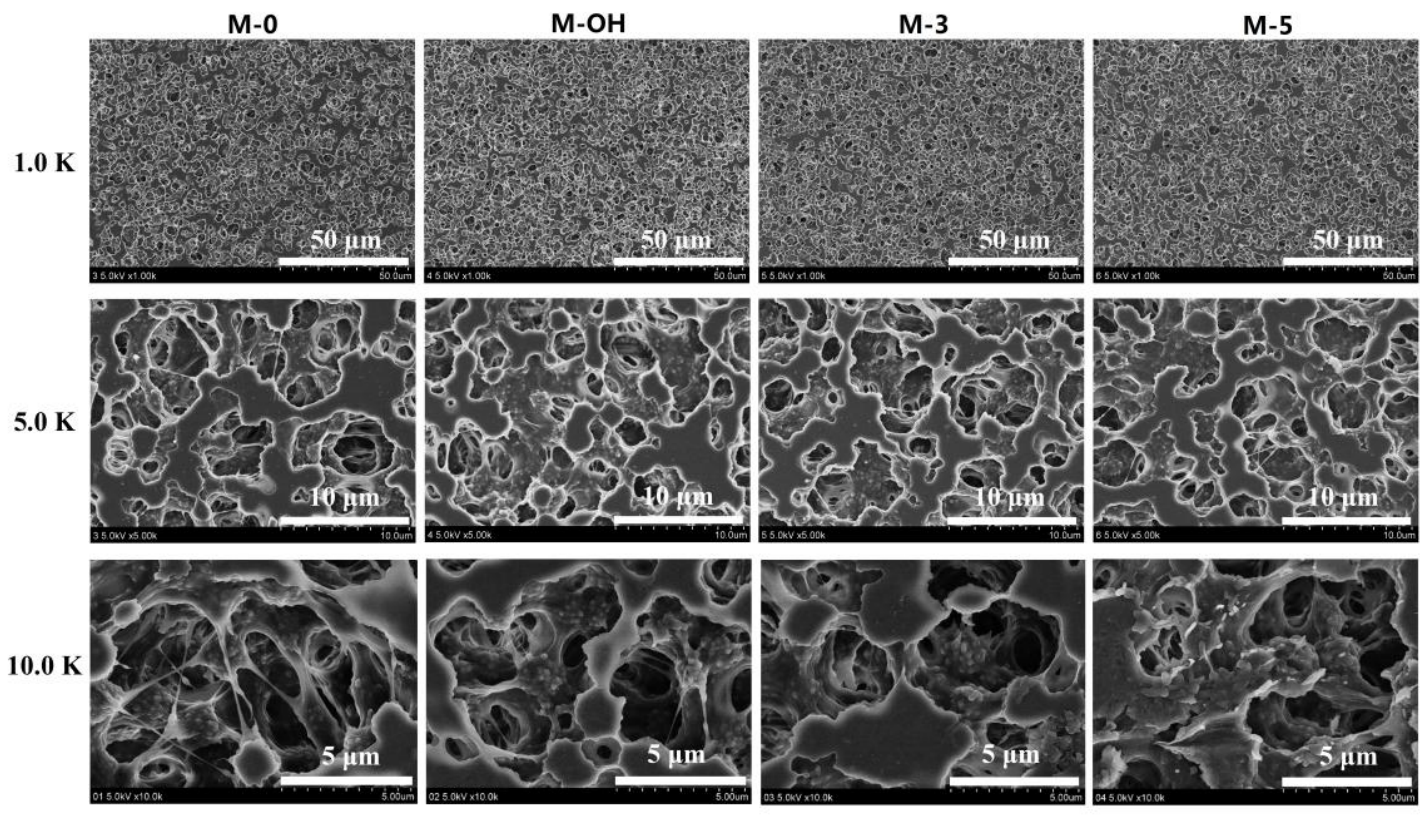

Fig. 6. SEM images of the surface morphology of the virgin and modified membranes.
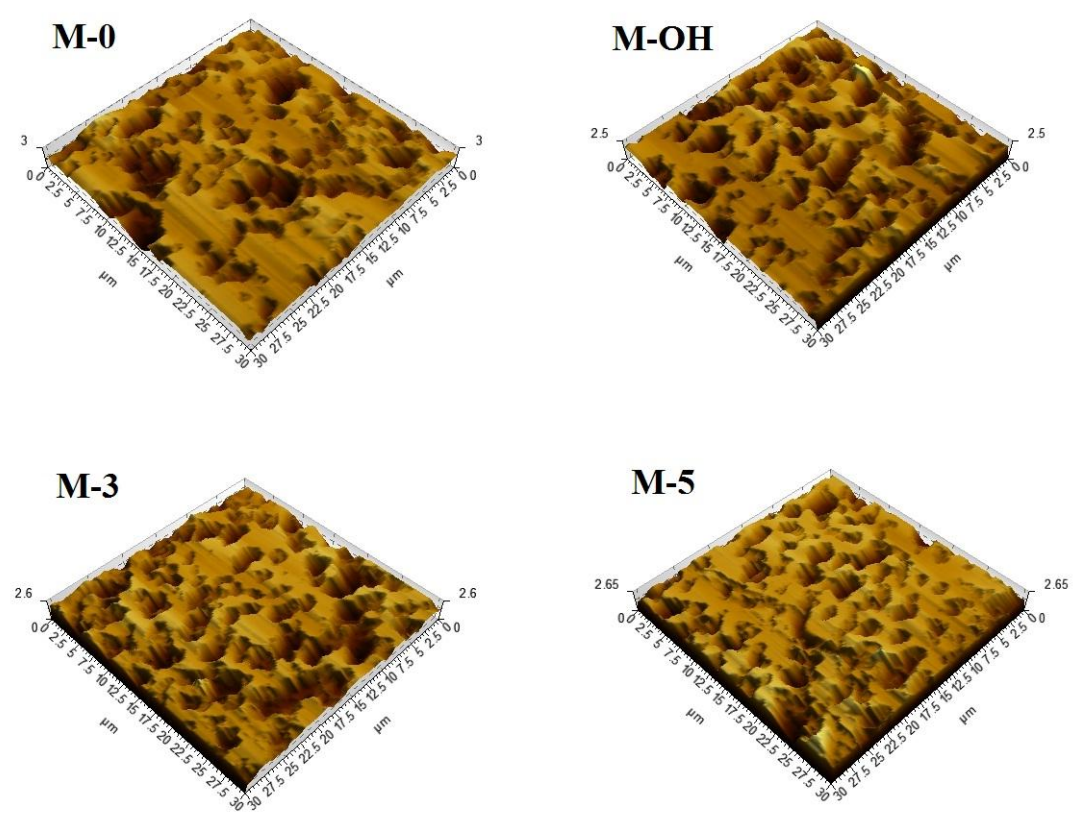

Fig. 7. Three-dimensional AFM images of the virgin and modified membranes. 


\subsection{Membrane hydrophilicity}

Fig. 8 exhibits the wetting ability of virgin and modified membranes. Water contact angle (WCA) of the virgin membrane is as high as $121.6^{\circ}$, which is decreased slightly to $100.8^{\circ}$ after plasma treatment due to the formation of polar groups on membrane surface. However, the water contact angle is declined significantly to as low as $29^{\circ}$ for the membrane of M-5, indicating that the incorporation of pLysAA brushes improves the wetting ability of the hydrophobic PVDF membrane remarkably due to the rough surface and the excellent hydration capacity of zwitterion and amide groups in the brushes, which can bind lots of water molecules through electrostatic and hydrogen bonding interactions.

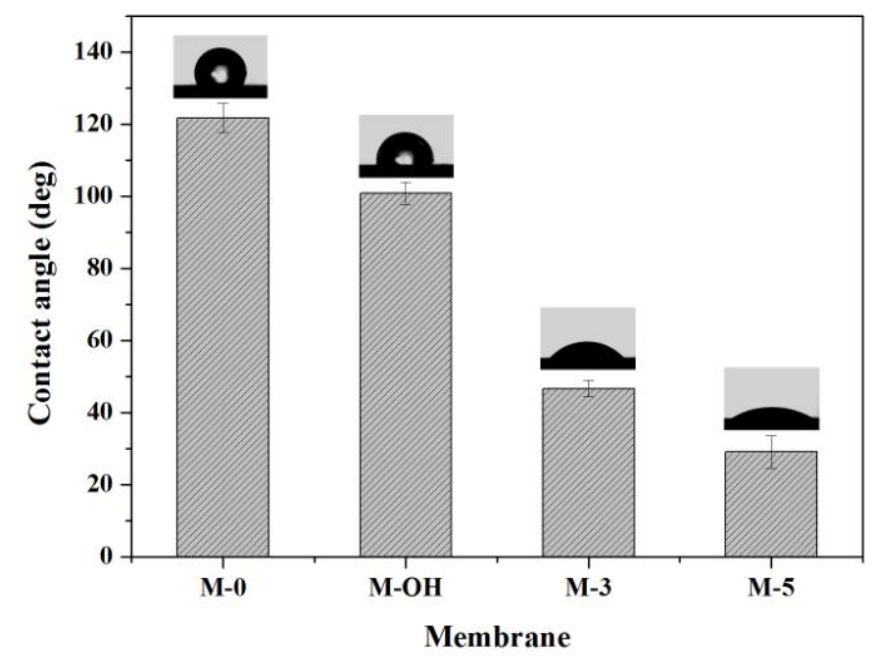

Fig. 8. Water contact angle of the virgin and modified membranes.

\subsection{Mechanical properties}

The mechanical properties of the virgin and modified membranes were characterized, as shown in Table 2. All of the membranes show a relative high tensile 
strength of more than $10 \mathrm{MPa}$. The modified membranes show even higher elongation at break than that of the virgin membrane due to the enhanced hydration capacity. These results demonstrate that the new membranes have sufficient mechanical strength for microfiltration application in a cross flow situation.

Table 2 Average pore size, surface roughness, mechanical properties and water uptake of the membranes.

\begin{tabular}{cccccc}
\hline Membrane & $\begin{array}{l}\text { Average pore } \\
\text { size }(\mu \mathrm{m})\end{array}$ & $\begin{array}{l}\text { Surface } \\
\text { roughness }(\mu \mathrm{m})\end{array}$ & $\begin{array}{l}\text { Tensile strength } \\
(\mathrm{MPa})\end{array}$ & $\begin{array}{l}\text { Breakage } \\
\text { elongation }(\%)\end{array}$ & $\begin{array}{l}\text { Water uptake } \\
\left(\mathrm{mg} \cdot \mathrm{cm}^{-2}\right)\end{array}$ \\
\hline M-0 & 0.223 & 0.598 & $10.25 \pm 0.57$ & $13.81 \pm 0.33$ & 2.01 \\
M-OH & 0.232 & 0.614 & $10.12 \pm 0.44$ & $17.43 \pm 0.41$ & 2.08 \\
M-3 & 0.227 & 0.622 & $10.31 \pm 0.68$ & $18.65 \pm 0.53$ & 2.29 \\
M-5 & 0.221 & 0.607 & $10.85 \pm 0.80$ & $20.07 \pm 0.49$ & 2.58 \\
\hline
\end{tabular}

\subsection{Permeation and antifouling performance}

In order to evaluate the permeation and the antifouling performance of the virgin and modified membranes, BSA adsorption and filtration tests of BSA solution and oil/water emulsion were conducted. As shown in Fig. 9, BSA adsorption of the graft membranes is decreased significantly to as low as $15 \mu \mathrm{g} \cdot \mathrm{cm}^{-2}$. After the introduction of zwitterionic brushes, surface of the graft membranes may preferably absorb water molecule rather than BSA due to the enhanced wetting ability of the membranes. As a result, BSA adsorption was suppressed to some extent. 


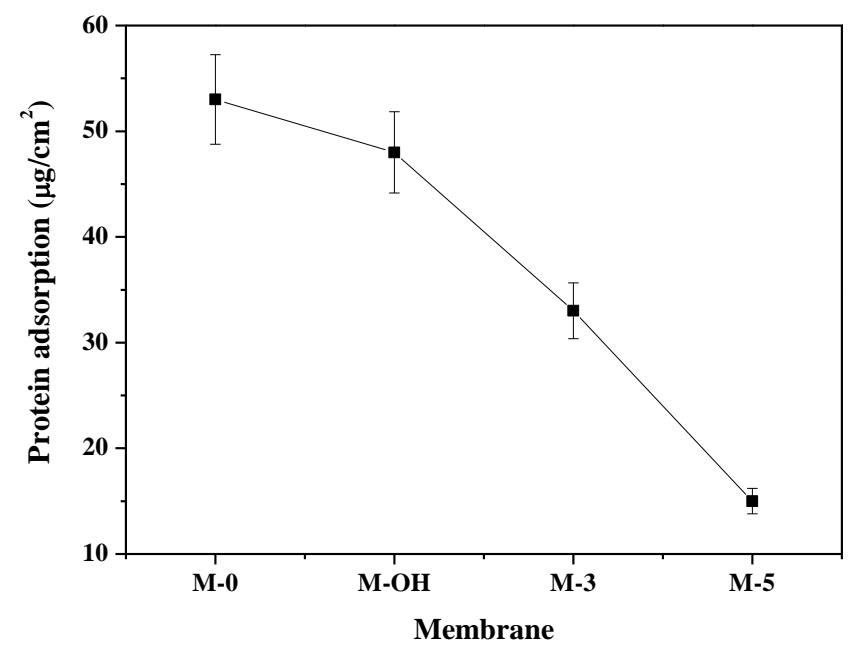

Fig. 9. Protein adsorption on the surface of the virgin and modified membranes.

As shown in Fig. 10A, water flux of the virgin membrane is $1580 \mathrm{~L} \cdot \mathrm{m}^{-2} \cdot \mathrm{h}^{-1}$, which is increased slightly to $1670 \mathrm{~L} \cdot \mathrm{m}^{-2} \cdot \mathrm{h}^{-1}$ after plasma treatment due to the increased hydrophilicity of the membrane surface. After grafted with zwitterionic pLysAA brushes, water flux of the membranes is increased significantly as the grafting yield increased. A similar trend can be observed with the fluxes of BSA solution. The flux of BSA solution is increased from $750 \mathrm{~L} \cdot \mathrm{m}^{-2} \cdot \mathrm{h}^{-1}$ for the virgin membrane to 1620 $\mathrm{L} \cdot \mathrm{m}^{-2} \cdot \mathrm{h}^{-1}$ for the graft membrane. The increased flux is mainly ascribed to the enhanced hydrophilicity, which lowers the resistance between the membrane surface and water molecules. Fouling tests exhibit that water flux recovery ratio of the membranes is increased from $50.6 \%$ to $86.0 \%$ after grafting polymerization. The reversible fouling ratio $\left(R_{r}\right)$ is increased from $3.1 \%$ to $24.9 \%$ and the irreversible fouling ratio $\left(\mathrm{R}_{\mathrm{ir}}\right)$ is decreased from $49.4 \%$ to $14.0 \%$, as shown in Fig. 10C and Fig. 10D. These results indicate that protein fouling of the graft membranes has been greatly restrained after grafting zwitterionic pLysAA brushes on membrane surface. 

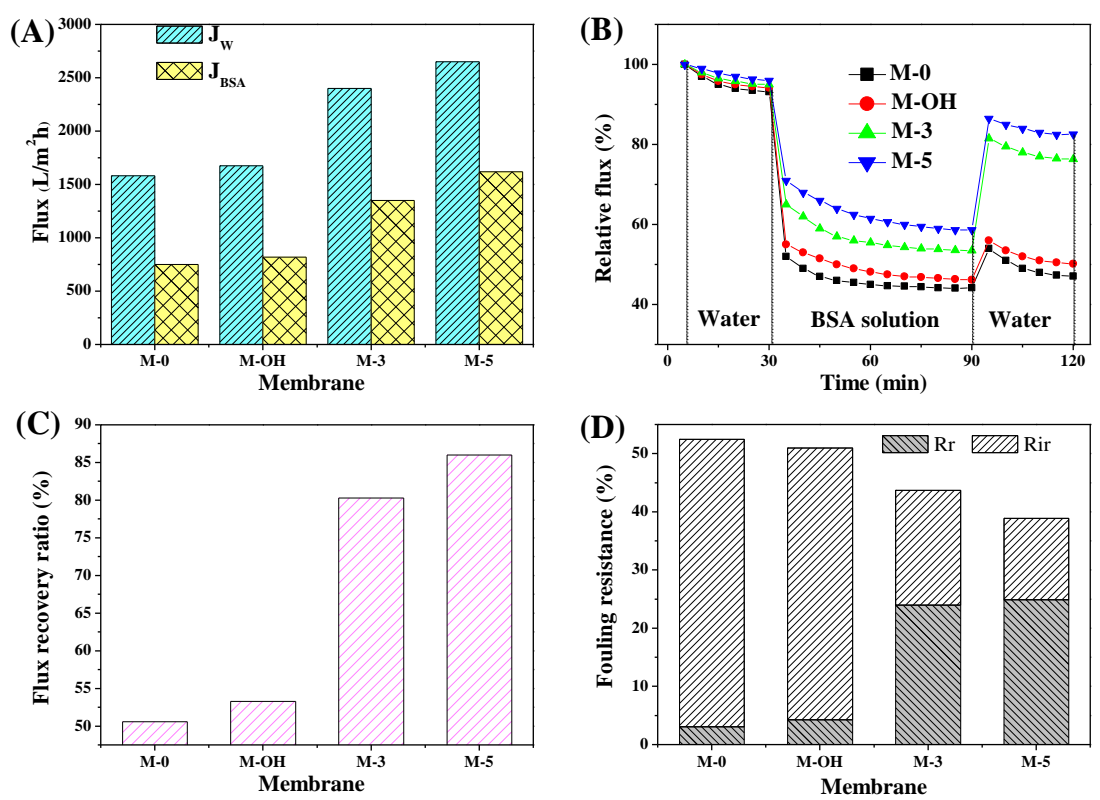

Fig. 10. (A) Water flux and BSA solution flux of the virgin and modified membranes. (B) Time-dependent relative flux during filtration of BSA solution. (C) Flux recovery ratio of the virgin and modified membranes. (D) Reversible and irreversible fouling ratio with BSA as the foulant.

Oil fouling is one of the biggest challenges for the separation of oil/water emulsion. Compared with protein fouling, which is prone to form fouling spots on membrane surface, oil fouling tends to coalesce, spread, migrate and form an oil layer eventually [38]. Therefore, the permeation and antifouling performance of the virgin and modified membranes with oil/water emulsion as the feed was also studied. As illustrated in Fig. 11B, the oil/water emulsion flux is increased from only 280 $\mathrm{L} \cdot \mathrm{m}^{-2} \cdot \mathrm{h}^{-1}$ for the virgin membrane to as high as $840 \mathrm{~L} \cdot \mathrm{m}^{-2} \cdot \mathrm{h}^{-1}$ for the graft membranes, which is mainly attributed to the increased hydrophilicity and almost unchanged pore size of the graft membranes. After grafted with pLysAA, the oil rejection ratio of the membranes is increased slightly as the grafting yield increased. This change is mainly attributed to the decrease in the effective pore size caused by the increased 
hydrophilicity of the surface. It should be noted that all the membranes can separate oil droplets from the oil/water emulsion effectively including the virgin membrane (as shown in Fig. 12). This can be explained by the average pore size of the membranes i.e. $\sim 0.2 \mu \mathrm{m}$, which is much smaller than that of the oil droplets i.e. $0.46-1.75 \mu \mathrm{m}$ as shown in Fig. 11A.
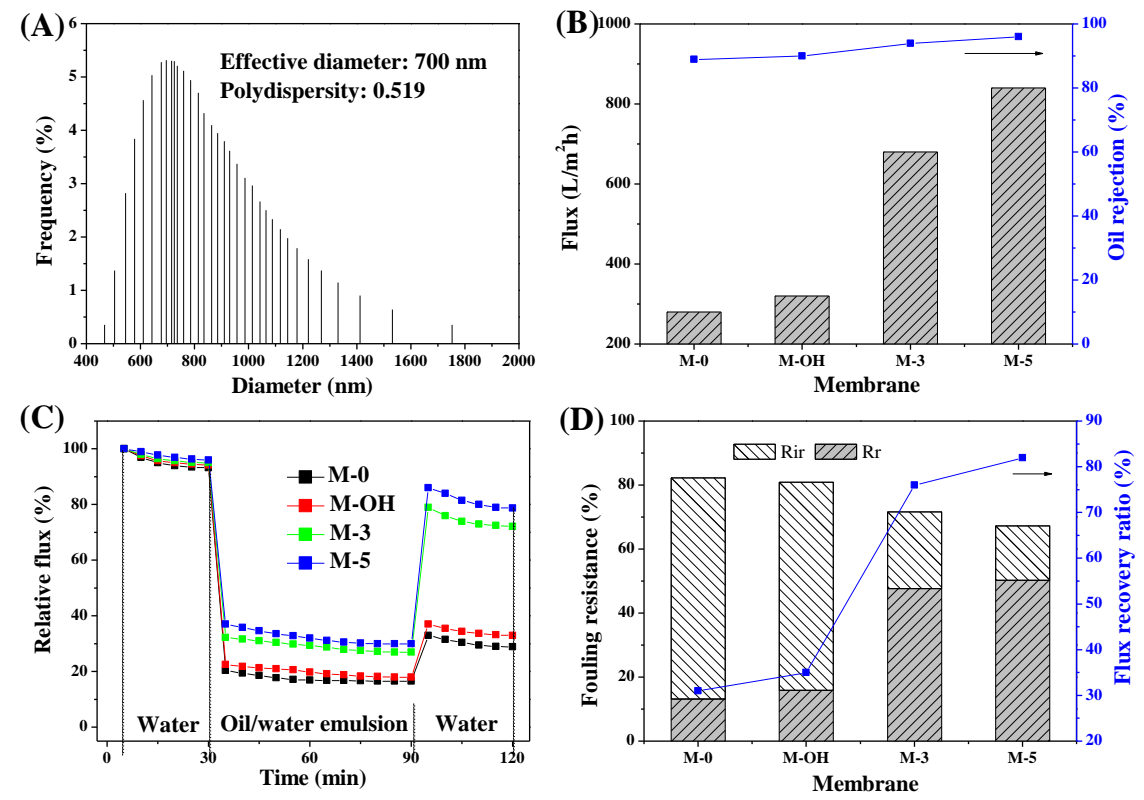

Fig. 11. (A) Size distribution of oil droplets in the soybean oil/water emulsion. (B) Oil/water emulsion flux and oil rejection values of the virgin and modified membranes. (C) Time-dependent relative flux during filtration of oil/water emulsion. (D) Flux recovery ratio, reversible and irreversible fouling ratio with oil/water emulsion as the foulant. 

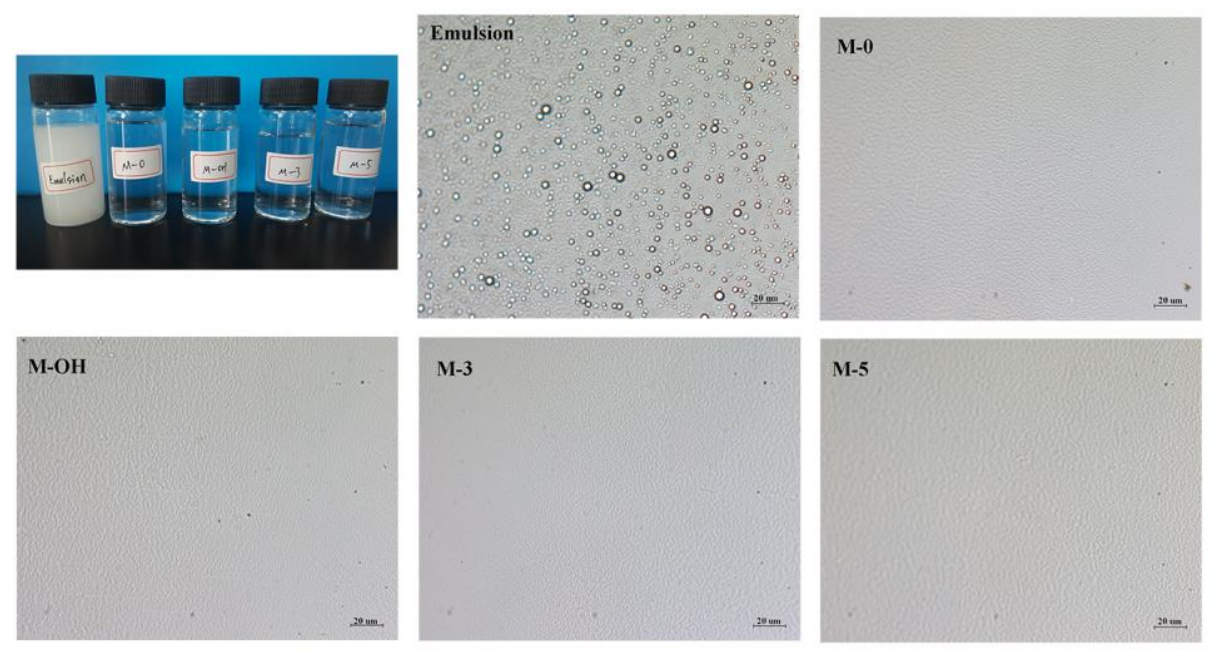

Fig. 12. Photograph of separation results of the oil/water emulsion by the virgin and modified membranes.

Fouling tests show that flux recovery ratio of the membranes is increased from only $31 \%$ for the virgin membrane to as high as $82 \%$ for the graft membrane, as illustrated in Fig. 11D. The value of reversible fouling ratio for the graft membranes is increased while that of the irreversible fouling ratio is decreased significantly. It is suggested that the graft membranes show strong resistance against oil fouling while the virgin membrane is easily fouled by oil, which is in accordance with that in protein filtration. It is implied that a hydration layer can be formed on the surface due to the electrostatic and hydrogen bonding interactions between water molecules and zwitterionic brushes. This hydrophilic layer can lower the resistance between water molecule and membrane surface resulting in increased fluxes of the graft membranes, and protect the membrane from hydrophobic contaminants resulting in increased flux recovery ratio and reversible fouling ratio.

\section{Conclusions}


Antifouling PVDF membrane was fabricated through surface activation and surface grafting of zwitterionic poly(lysine methacrylamide) brushes via a combination of atmospheric plasma treatment and SI-ATRP. The immobilization of zwitterionic pLysAA brushes on membrane surface was confirmed by ATR-FTIR and XPS analysis. With proper grafting yield, the hydrophilicity, permeation and antifouling properties of the resulting membranes were improved significantly after the grafting polymerization. This study provides useful information for the fabrication of antifouling PVDF membrane with well-defined pLysAA brushes, and the modified membranes may find applications in blood purification, water treatment and oil/water separation, etc.

\section{Acknowledgment}

This work is supported by grants from the National Science Foundation of China (No. 21174027), Program for New Century Excellent Talents in University (No. NCET-12-0827) and Program of Introducing Talents of Discipline to Universities (No. 111-2-04).

\section{References}

[1] Q. Li, Q.Y. Bi, H.H. Lin, L.X. Bian, X.L. Wang, A novel ultrafiltration (uf) membrane with controllable selectivity for protein separation, J. Membr. Sci. 427 (2013) 155-167.

[2] W. Guo, H.H. Ngo, J. Li, A mini-review on membrane fouling, Bioresour. Technol. 122 (2012) 27-34.

[3] M.A. Shannon, P.W. Bohn, M. Elimelech, J.G. Georgiadis, B.J. Marinas, A.M. Mayes, Science and technology for water purification in the coming decades, Nature 452 (2008) 301-310.

[4] D. Rana, T. Matsuura, Surface modifications for antifouling membranes, Chem. Rev. 110 (2010) 2448-2471. 
[5] A. Venault, M.R.B. Ballad, Y.H. Liu, P. Aimar, Y. Chang, Hemocompatibility of pvdf/ps-b-pegma membranes prepared by lips process, J. Membr. Sci. 477 (2015) 101-114.

[6] Y.F. Zhao, L.P. Zhu, Z. Yi, B.K. Zhu, Y.Y. Xu, Zwitterionic hydrogel thin films as antifouling surface layers of polyethersulfone ultrafiltration membranes anchored via reactive copolymer additive, J. Membr. Sci. 470 (2014) 148-158.

[7] T. Yuan, J. Meng, T. Hao, Y. Zhang, M. Xu, Polysulfone membranes clicked with poly (ethylene glycol) of high density and uniformity for oil/water emulsion purification: Effects of tethered hydrogel microstructure, J. Membr. Sci. 470 (2014) 112-124.

[8] F. Ran, S. Nie, W. Zhao, J. Li, B. Su, S. Sun, C. Zhao, Biocompatibility of modified polyethersulfone membranes by blending an amphiphilic triblock co-polymer of poly(vinyl pyrrolidone)-b-poly(methyl methacrylate)-b-poly(vinyl pyrrolidone), Acta Biomater. 7 (2011) 3370-3381.

[9] F. Ran, J. Li, Y. Lu, L. Wang, S. Nie, H. Song, L. Zhao, S. Sun, C. Zhao, A simple method to prepare modified polyethersulfone membrane with improved hydrophilic surface by one-pot: The effect of hydrophobic segment length and molecular weight of copolymers, Mater. Sci. Eng. 37 (2014) 68-75.

[10] H. Song, F. Ran, H. Fan, X. Niu, L. Kang, C. Zhao, Hemocompatibility and ultrafiltration performance of surface-functionalized polyethersulfone membrane by blending comb-like amphiphilic block copolymer, J. Membr. Sci. 471 (2014) 319-327.

[11] W. Li, J. Zhou, J.S. Gu, H.Y. Yu, Fouling control in a submerged membrane-bioreactor by the membrane surface modification, J. Appl. Polym. Sci. 115 (2010) 2302-2309.

[12] Z. Xue, S. Wang, L. Lin, L. Chen, M. Liu, L. Feng, L. Jiang, A novel superhydrophilic and underwater superoleophobic hydrogel-coated mesh for oil/water separation, Adv. Mater. 23 (2011) 4270-4273.

[13] Y. Sui, X. Gao, Z. Wang, C. Gao, Antifouling and antibacterial improvement of surface-functionalized poly(vinylidene fluoride) membrane prepared via dihydroxyphenylalanine-initiated atom transfer radical graft polymerizations, J. Membr. Sci. 394-395 (2012) 107-119.

[14] J. Ju, C. Wang, T. Wang, Q. Wang, Preparation and characterization of ph-sensitive and antifouling poly(vinylidene fluoride) microfiltration membranes blended with poly(methyl methacrylate-2-hydroxyethyl methacrylate-acrylic acid), J. Colloid Interface Sci. 434 (2014) 175-180.

[15] Y. Sui, Z. Wang, X. Gao, C. Gao, Antifouling pvdf ultrafiltration membranes incorporating pvdf-g-phema additive via atom transfer radical graft polymerizations, J. Membr. Sci. 413-414 (2012) $38-47$.

[16] T. Mohan, R. Kargl, K.E. Tradt, M.R. Kulterer, M. Braćić, S. Hribernik, K. Stana-Kleinschek, V. Ribitsch, Antifouling coating of cellulose acetate thin films with polysaccharide multilayers, Carbohydr. Polym. 116 (2015) 149-158.

[17] T. Xiang, R. Wang, W.F. Zhao, S.D. Sun, C.S. Zhao, Covalent deposition of zwitterionic polymer and citric acid by click chemistry-enabled layer-by-layer assembly for improving the blood compatibility of polysulfone membrane, Langmuir 30 (2014) 5115-5125.

[18] R. Zhou, P.F. Ren, H.C. Yang, Z.K. Xu, Fabrication of antifouling membrane surface by poly(sulfobetaine methacrylate)/polydopamine co-deposition, J. Membr. Sci. 466 (2014) 18-25.

[19] Y.C. Chiang, Y. Chang, A. Higuchi, W.Y. Chen, R.C. Ruaan, Sulfobetaine-grafted poly(vinylidene fluoride) ultrafiltration membranes exhibit excellent antifouling property, J. Membr. Sci. 339 (2009) 
151-159.

[20] H. Meng, Q. Cheng, C. Li, Polyacrylonitrile-based zwitterionic ultrafiltration membrane with improved anti-protein-fouling capacity, Appl. Surf. Sci. 303 (2014) 399-405.

[21] Q. Zhou, X.P. Lei, J.H. Li, B.F. Yan, Q.Q. Zhang, Antifouling, adsorption and reversible flux properties of zwitterionic grafted pvdf membrane prepared via physisorbed free radical polymerization, Desalination 337 (2014) 6-15.

[22] S. Nishigochi, T. Ishigami, T. Maruyama, Y. Hao, Y. Ohmukai, Y. Iwasaki, H. Matsuyama, Improvement of antifouling properties of polyvinylidene fluoride hollow fiber membranes by simple dip coating of phosphorylcholine copolymer via hydrophobic interactions, Ind. Eng. Chem. Res. 53 (2014) 2491-2497.

[23] M. Hadidi, A.L. Zydney, Fouling behavior of zwitterionic membranes: Impact of electrostatic and hydrophobic interactions, J. Membr. Sci. 452 (2014) 97-103.

[24] Q. Shi, Y. Su, W. Chen, J. Peng, L. Nie, L. Zhang, Z. Jiang, Grafting short-chain amino acids onto membrane surfaces to resist protein fouling, J. Membr. Sci. 366 (2011) 398-404.

[25] F. Li, J. Ye, L. Yang, C. Deng, Q. Tian, B. Yang, Surface modification of ultrafiltration membranes by grafting glycine-functionalized pva based on polydopamine coatings, Appl. Surf. Sci. 345 (2015) 301-309.

[26] Y. Chang, Y.J. Shih, C.J. Lai, H.H. Kung, S. Jiang, Blood-inert surfaces via ion-pair anchoring of zwitterionic copolymer brushes in human whole blood, Adv. Funct. Mater. 23 (2013) 1100-1110.

[27] I. Banerjee, R.C. Pangule, R.S. Kane, Antifouling coatings: Recent developments in the design of surfaces that prevent fouling by proteins, bacteria, and marine organisms, Adv. Mater. 23 (2011) 690-718.

[28] A.M. Alswieleh, N. Cheng, I. Canton, B. Ustbas, X. Xue, V. Ladmiral, S. Xia, R.E. Ducker, O. El Zubir, M.L. Cartron, C.N. Hunter, G.J. Leggett, S.P. Armes, Zwitterionic poly(amino acid methacrylate) brushes, J. Am. Chem. Soc. 136 (2014) 9404-9413.

[29] R.N. Keller, H.D. Wycoff, L.E. Marchi, Copper (i) chloride, Inorg. Synth. 2 (1946) 1-4.

[30] S. Nagaoka, A. Shundo, T. Satoh, K. Nagira, R. Kishi, K. Ueno, K. Iio, H. Ihara, Method for a convenient and efficient synthesis of amino acid acrylic monomers with zwitterionic structure, Synth. Conmmun. 35 (2005) 2529-2534.

[31] Q. Liu, W. Li, A. Singh, G. Cheng, L. Liu, Two amino acid-based superlow fouling polymers: Poly(lysine methacrylamide) and poly(ornithine methacrylamide), Acta Biomater. 10 (2014) 2956-2964.

[32] R.G. Nuzzo, G. Smolinsky, Preparation and characterization of functionalized polyethylene surfaces, Macromolecules 17 (1984) 1013-1019.

[33] G.J.G. Davies, D.P. Knight, F. Vollrath, Chitin in the silk gland ducts of the spider nephila edulis and the silkworm bombyx mori, PLoS ONE 8 (2013) 1-7.

[34] R. Kumar, A.F. Ismail, Fouling control on microfiltration/ultrafiltration membranes: Effects of morphology, hydrophilicity, and charge, J. Appl. Polym. Sci. 132 (2015) 42042.

[35] J.H. Jiang, L.P. Zhu, X.L. Li, Y.Y. Xu, B.K. Zhu, Surface modification of pe porous membranes based on the strong adhesion of polydopamine and covalent immobilization of heparin, J. Membr. Sci. 364 (2010) 194-202.

[36] A. Venault, Y. Chang, H.S. Yang, P.Y. Lin, Y.J. Shih, A. Higuchi, Surface self-assembled zwitterionization of poly(vinylidene fluoride) microfiltration membranes via hydrophobic-driven coating for improved blood compatibility, J. Membr. Sci. 454 (2014) 253-263. 
[37] F. Liu, N.A. Hashim, Y. Liu, M.R.M. Abed, K. Li, Progress in the production and modification of pvdf membranes, J. Membr. Sci. 375 (2011) 1-27.

[38] J. Peng, Y. Su, W. Chen, X. Zhao, Z. Jiang, Y. Dong, Y. Zhang, J. Liu, X. Fan, Antifouling membranes prepared by a solvent-free approach via bulk polymerization of 2-hydroxyethyl methacrylate, Ind. Eng. Chem. Res. 52 (2013) 13137-13145. 
Plasma

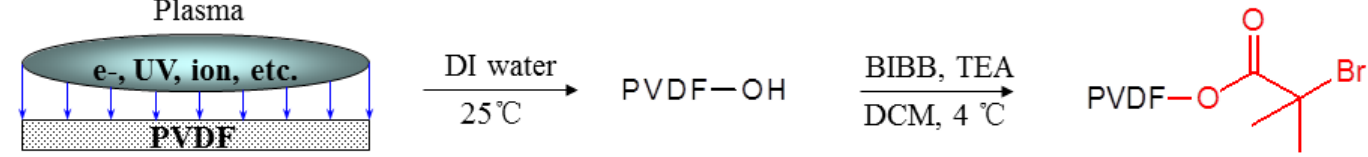

Protein Oil droplet

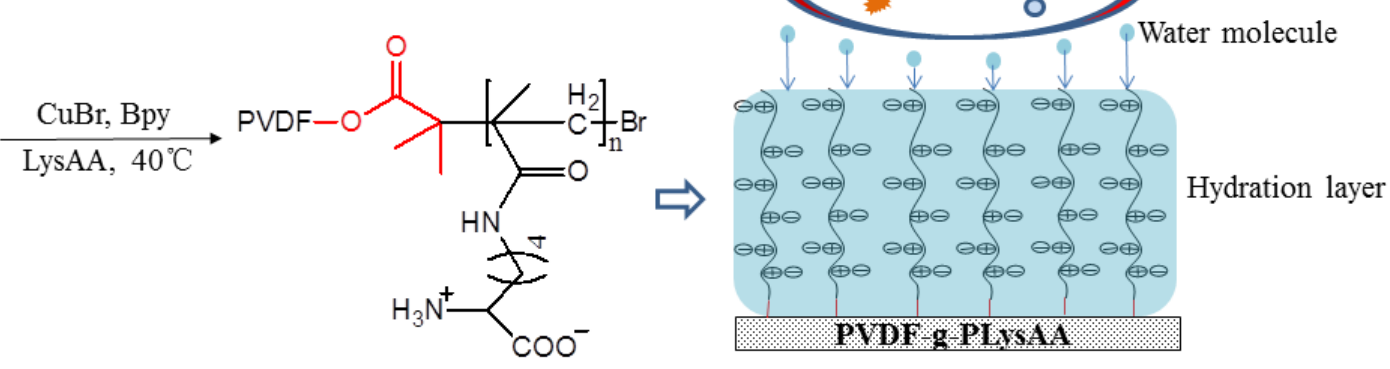

